\title{
The importance of being irregular
}

\author{
Karen De Clercq \\ CNRS/Laboratoire de linguistique formelle/Université de Paris \\ karendc1981@gmail.com
}

How to cite: De Clercq, Karen. 2021. The importance of being irregular. Isogloss. Open Journal of Romance Linguistics 7, 16: 1-5.

The answer to the question whether morphological irregularities are to be analyzed as exceptions, or whether we should try to find regularity depends a lot on one's objectives. One can simply focus on the difference of the forms, or, alternatively, take them to be a window onto the underlying structure.

Michal Starke shows clearly in his NELS talk (Starke 2020) that irregular forms in the French verbal system can reveal a lot about the underlying features of all verbs, and that an analysis that uncovers this can be rewarding to get closer to an understanding of how features are ordered in a particular language, and in language in general. Irregularity is thus used as a tool in nanosyntax, just like syncretisms and ambiguous readings, to probe the features that together constitute the functional sequence or $f$ seq. Starke (2020) uses an irregular verb to help to pin down the position of a subjunctive mood feature. A summary of the reasoning goes as follows. The regular paradigm of the subjunctive present looks exactly the same as the paradigm of the indicative, apart from the appearance of the $-i$ - after the root in the $1^{\text {st }}$ and $2^{\text {nd }}$ person plural of the subjunctive present, as in subjunctive 1PL aim-i-ons vs indicative 1PL aim-ons (and similarly 2PL aim-i-ez vs aim-ez). Starke identifies $-i$ - as the lexicalization of TENSE in the paradigm of the present subjunctive, while the agreement endings lexicalize TENSE as portmanteaus in 1, 2, $3 \mathrm{SG}$ of the present indicative and subjunctive. Since that same $-i$-also pops up in the past indicative 1PL and 2PL, Starke argues that $-i$ - not only lexicalises TENSE, but that it can also lexicalise PAST (with PAST being a shorthand to refer to the feature that gives rise to past tense). The fact that the irregular verb savoir has a dedicated form that is used in the subjunctive, i.e. sach- (saš in IPA light, as in 
Starke's talk), that appears below - $i$ - in the subjunctive present, i.e. 1PL sach-i-ons vs indicative sav-ons, allows Starke to derive the fact that a subjunctive feature, i.e. [Mood], is located below Tense in the subjunctive present. The root saš- in fact lexicalises all features related to Aspect and Aktionsart up to a [Mood] feature, but it does not lexicalise an additional indicative feature [Ind], which regular roots like aim- lexicalize in addition. As such, Starke manages to capture the underlying structure of the verbal sequence thanks to the presence of irregular verbs.

However, the fact that nanosyntax looks for regularity underneath surface irregularity does not mean that irregularity has no place in the system. Irregularity (in roots or affixes) is cashed out in the system as the presence of lexically related lexical items whose structural size differs. With respect to the example discussed, savoir is perceived as an irregular verb because there is more than one root stored in the lexicon for the concept KNOW. Zooming in on three different roots of savoir, the root $s \varepsilon$ - (IPA for sais, sais, sait) is used in 1SG, 2SG and 3SG of the present indicative, spelling out a whole chunk of structure up to the agreement features, while the root sav-, being structurally smaller, is used in all other forms of the present indicative, and the entire past indicative. The third root, saš-, will win the competition from $s a v$ - and $s \varepsilon$ - in contexts where an indicative feature is absent in syntax. A verb like aimer does not have related but different roots in the lexicon, hence no competition will arise between the roots, and the verb will be perceived as regular.

No matter though whether the lexicon contains additional roots like saš- and $s \varepsilon$ - or only one root like aim-, the same regular and universal underlying features will be associated with the expression of the subjunctive mood, regardless of the form of the root involved. This method of tackling irregulars to probe the underlying structure of language is not only fruitful for the exploration of the TAM domain in French. It has also proven an efficient means to explore the irregularities in the adjectival degree system of Czech (Caha, De Clercq and Vanden Wyngaerd (2019) and Latin (De Clercq and Vanden Wyngaerd 2017). To be more concrete, the regular ending of the Czech comparative $\check{e} j-\check{s}$ is always reduced to $-\check{s}$ - in the presence of suppletive adjectival roots. The adjective dobr-y 'good', for instance, has the suppletive comparative lep-š- $i$ 'better'. In combination with other distributional data of the comparative morphemes in Czech, Caha, De Clercq and Vanden Wyngaerd (2019) take this as support to decompose [CMPR] in two heads, [C1] and [C2]. Similarly, De Clercq and Vanden Wyngaerd (2017) decompose the regular superlative marker of Latin in two pieces on the basis of the systematic disappearance of one of these two pieces with suppletive roots. The regular superlative of altus 'tall' is alt-i-ss-im-us 'tallest'. Abstracting away from the - $i$ - for now, which De Clercq \& Vanden Wyngaerd analyze as the comparative marker, and the agreement marker $-u s$, one of the two bits of the superlative, i.e. -ss-, disappears systematically in the superlative of the following adjectives bonus 'good', magnus 'big', parvus 'small' and multus 'much', resulting in the superlative forms opt-im-us, maks-im-us, min-im-us and plur-im-us, respectively.

The same type of approach is deployed in my own project on the allomorphy of TAM markers induced by negation and the allomorphy of negation induced by TAM. The aim is to probe the underlying structure of negation, its position(s) in the TAM-sequence and the TAM-sequence itself (see De Clercq 2020 for a first outline of the project). The type of suppletion that arises under negation is a different type 
of irregularity than what we discussed for the French irregular verbs. Miestamo (2005) would refer to is as an asymmetry, in the sense that it is the presence of negation that changes the way the TAM-domain gets lexicalized in an affirmative clause/phrase. To illustrate this, let us consider evidence from Bambara, a NigerCongo language spoken in Mali, which features several suppletive negative markers (Dumestre 2003), but we will only focus on one of them in this reply. To negate a present tense indicative, the marker of the present tense, $b \varepsilon$, (1a) becomes $t \varepsilon,(2 a)$.
a. Sanu be baara ke.
Sanu PRS work do
'Sanu works.'
b. Sanu te baara ke.
Sanu PRS.NEG work do
'Sanu does not work.'

(Ermisch 2013: 2)

In the past tense the same marker $b \varepsilon$ is used, but an additional past tense morpheme, tun, is added, (2a). Under negation the same suppletive negative form $t \varepsilon$ is used as in the present, in combination with the past tense marker tun (2b).
a. N tun be liburu kalan.
1SG PST PRSbook read
'I was reading the book. /I used to read the book.'
b. $\mathrm{N}$ tun te liburu kalan.
1SG PST PRS.NEG book read
'I was not reading the book.'
(Ermisch 2013:4)

What these data show is that the distinction between a feature for (default, present) TENSE and a feature for PAST, which features in Starke's (2020) analysis of the French verbal system, is confirmed on the basis of the data from Bambara. While $b \varepsilon$ realizes present tense, the fact that it is included in the lexicalization of the past tense, suggests that it must be a default tense feature, making it the prefixal counterpart of the French $-i$-. However, while $-i$ - in French can also lexicalise PAST, this job needs to be done by tun in Bambara. Crucially, these data also show that this default TENSE feature is also present in the lexicalisation of sentential negation, supporting long-standing intuitions in the literature on the relevance of tense for the expression of sentential negation (Zanuttini 1996). While these data do not allow us to decide whether negation sits higher or lower than default TENSE, they show that 1) negative markers can lexicalise more than one feature, and 2) that there is a default TENSE feature that not only gives rise to present tense, but that is also included in the lexicalization of the past tense.

As a final note, I want to make explicit an agenda that is often tacitly underlying a lot of theoretical work in linguistics and which may also be hidden in the question this reply started out with. This hidden agenda has to do with how much a theoretical model or analysis does justice to the representation of regularities and irregularities in the minds of adults and children, i.e. how much the model is a model of actual brain processes, or of how the lexicon is mentally represented. Even if a theoretical model is not originally conceived as a means to 
capture the psychological or neurological reality as such, very often arguments related to processing and acquisition are used to support various claims in theoretical models and to win against other models in debates, making the similarity to what actually happens in the brain a much more important part of most models than is often openly admitted. In this respect, it may be worthwhile pointing out that recent work by Meunier and Marslen-Wilson (2004) on regularity and irregularity in French verbal morphology shows that regular and irregular verb forms in French are equally good primes for their corresponding verb stems, i.e. irregular buvons primes boire as good as regular aimons primes aimer, thus providing some additional support - from psycholinguistics - for the idea, worked out in Starke's NELS talk, that there may be more regularity in irregulars than meets the eye.

\section{References}

Caha, Pavel, De Clercq, Karen and Vanden Wyngaerd, Guido. 2019. The fine structure of the comparative. Studia Linguistica 73 (3): 470-521.

De Clercq, Karen. 2020. Tense and sentential negation. A typological perspective. Linguistics in the Netherlands 37, ed. by Elena Tribushinina and Mark Dingemanse, 71-89.

De Clercq, Karen and Vanden Wyngaerd, Guido, 2017. *ABA revisited: Evidence from Czech and Latin degree morphology.

$\begin{array}{lllll}\text { Glossa: a journal of general linguistics, } & 2(1), \quad 69 .\end{array}$ DOI: http://doi.org/10.5334/gjgl.371

Dumestre, Gérard. 2003. Grammaire fondamentale du bambara. Paris: Karthala.

Ermisch, Sonja. 2013. The structure of Bambara. Handout. URL https://user.unifrankfurt.de/ tezimmer/HP FG-

RelS/PDF/The\%20Structure\%20of\%20Bambara_Handout_Budapest\%20Mai\%20 $\underline{\text { 2013.pdf }}$

Meunier, Fanny and Marslen-Wilson, William. 2004. Regularity and irregularity in French verbal inflection. Language and Cognitive Processes 19 (4): 561-580.

Miestamo, Matti. 2005. Standard Negation. The Negation of Declarative Verbal Main Clauses in a Typological Perspective. Berlin: Mouton de Gruyter.

Starke, Michal. 2020. Universal Morphology. Invited talk at NELS 51 (6-8 November 2020). Université du Québec à Montréal, Canada (Online conference).

Zanuttini, Raffaella. 1996. On the relevance of tense for sentential negation. Parameters and Functional Heads, ed. by Adriana Belletti \& Luigi Rizzi, 181 -208. Oxford: Oxford University Press. 